\title{
trolk MOTIF BATIK KASIH SAYANG IBU UNTUK MEMAKNAI HARI IBU
}

Volume 1, Nomor 1

Juli 2019,

(7-12)

\author{
Fegelia Rahmadani \\ Program Studi Kriya Tekstil, Fakultas Pasca Sarjana, \\ Institut Seni Indonesia Yogyakarta \\ e-mail : pps_isiyk@yahoo.com
}

\begin{abstract}
ABSTRAK
Mengamati peristiwa peringatan Hari Ibu, yang jatuh pada tanggal 22 Desember sebagai Hari Ibu Nasional di negara Indonesia. Dewasa ini, makna dari moment Hari Ibu serta esensinya telah banyak berubah dan bergeser. Dimana peringatan Hari Ibu sekarang hanya pada hal-hal yang seremonial dan temporal, sepeti ucapan selamat via media sosial. Memaknai Hari Ibu dengan memberikan kasih sayang, merupakan suatu ungkapan yang indah. Semua manusia dan makhluk hidup di dunia ini memerlukan kasih sayang, tak terkecuali. Kasih sayang ibu terhadap anaknya tidak akan sama dengan kasih sayang anak kedapada ibunya. Seperti peribahasa "kasih ibu sepanjang jalan, kasih anak sepanjang galah" dari arti kata yang digunakan yaitu "jalan dan galah", jalan selau berkaitan dengan jalan lain sehingga tidak berujung. Sementara galah adalah sebuah tongkat yang memiliki ukuran tertentu yang dapat dilihat ujung dan pangkalnya. Dengan motif batik ini, ingin menyampaikan perasaan kasih sayang terhadap ibu sebagai bentuk apresiasi atas jasanya selama ini, dan juga ingin menyadarkan kaum millennial akan makna kasih sayang pada moment Hari Ibu, bukan sekedar ajang pencitraan di media sosial.
\end{abstract}

Kata kunci: Hari ibu, Ibu dan anak, Kasih sayang

\section{ABSTRACT}

Observed the Mother's Day memorial event, which falls on December 22 as National Mother's Day in the country of Indonesia. Today, the meaning of mom's Moment and its essence has changed and shifted. Where Mother's Day commemoration is now only on ceremonial and temporal matters, such as congratulations by social media. Meaning Mother's Day by giving affection, is a beautiful expression. All humans and living beings in this world need love, not exception. Mother's love for her child will not be the same as the child's love for her mother. Like the proverb "mother's love along the way, child love along the pole" from the meaning of the word used is "road and" pole ", the path is connected with another way so that no end. While the pole is a stick that has a certain size that can be seen end and base. With this pattern batik, want to convey feelings of affection for mother as a form of appreciation for his services so far, and also want to awaken the millennial will be the meaning of affection on the Moment, not just a social media imaging event.

Keywords: Mother's Day, Mother and child, Affection

\section{PENDAHULUAN}

Kata "batik" berasal dari bahasa Jawa, dari kata "amba" yang berarti menggambar dan "tik" yang berate kecil. Seperti misalnya terdapat dalam kata kata jawa lainnya yakni "klitik" (warung kecil), "klitik" (kutu kecil) dan sebagainya. (Teguh Suwarto, dkk, 1998 : hal 8).

Pengertian lain dari batik menjelaskan bahwa batik merupakan suatu seni dan cara menghias kain dengan penutup lilin / malam untuk membentuk corak ragam hiasnya membentuk sebuah bidang pewarnaan, sedangkan warna itu sendiri dicelup dengan menggunakan zat pewarna. (Endik, 1986 : hal 10).

Berdasarkan dua pengertian diatas dapat disimpulkan bahwa batik merupakan suatu proses seni menghias kain dengan menggambar pola tertentu diatas kain menggunakan malam.

Batik juga merupakan warisan asli budaya Indonesia yang telah diakui oleh UNISCO (United Nations Cultural Organization) sejak 2 Oktober 2009 sebagai warisan budaya tak benda. Karena proses membatik itu adalah salah satu kesenian bangsa Indonesia yang harus dilestarikan, agar batik tidak punah dan tetap menjadi identitas kebudayaan Indonesia.

Menurut prosesnya batik dapat dibagi menjadi tiga macam yaitu batik tulis, batik cap, dan batik kombinasi antara batik tulis dan cap. dengan adanya perkembangan teknologi untuk menghindari lamanya proses produksi batik, digunakan screen printing agar dapat mengefesienkan waktu. Walaupun begitu, produk ini tidak bisa dikatakan digolongkan sebagai suatu 
proses batik tetapi dinamakan tekstil motif batik atau batik printing.

Mengamati peristiwa peringatan Hari Ibu, kini makna serta esensinya telah banyak berubah dan bergeser. Dimana peringatan Hari Ibu sekarang hanya pada hal-hal yang seremonial dan temporal, seperti ucapan selamat via media sosial, sehari menyatakan rasa cinta terhadap kaum ibu, bertukar hadiah, lomba-lomba bernuansa ibu, seperti memasak, berdandan, memakai kebaya, dan lainnya.

Moment Hari Ibu bermula dari pertemuan antara para pejuang perempuan yang bertemu pada saat menghadiri acara Kongres Perempuan Indonesia I di Yogyakarta. Pada saat itu para pemimpin organisasi perempuan dari berbagai wilayah se-Indonesia berkumpul untuk menyatukan pikiran, rasa, karsa dan semangat perjuangan untuk mencapai kemerdekaan dan perbaikan nasib kaum perempuan agar setara dengan laki laki dan mendapatkan pendidikan yang sama. Karena dari ibu yang cerdas maka akan melahirkan anak yang cerdas pula. Dari penelitian penciptaan ini maka peneliti ingin menghasilkan suatu motif yang bisa menyampaikan bentuk kasih sayang anak terhadap ibu untuk memaknai momen hari ibu.

\section{KAJIAN PUSTAKA}

\section{Motif Batik}

S.K. Sewan Susanto (1980:261) berpendapat bahwa terdapat tiga unsur utama pada ragam hias batik yaitu,

a. Ornamen Utama.

Ornamen utama/pokok adalah suatu ragam hias yang menentukan motif sebuah batik mempunyai makna, sehingga dalam pemberian nama motif batik berdasarkan jiwa dan arti lambang yang ada pada motif tersebut. (S.K. Sewan Susanto,1980:261).

b. Ornamen tambahan

Ornamen tambahan/isian motif yaitu ornamen yang tidak mempunyai arti dalam pembentukan motif dan berfungsi sebagai pengisi bidang.

c. Isen-isen motif batik

Isen-isen motif batik yaitu unsur-unsur garis dan titik atau ornament tertentu yang berfungsi sebagai pengisi untuk melengkapi motif secara keseluruhan sehingga menimbulkan keindahan pada motif secara keseluruhan (S.K. Sewan Susanto, 1980:231).Isen dapat berbentuk titik dinamakan "cecek" dan garis yang dinamakan "sawut". Ornamen yang berfungsi sebagai isen berupa cabang-cabang tumbuh-tumbuhan yaitu daun, bunga, dan batang. Menciptakan motif kreasi baru merupakan inovasi hasil kreativitas penulis menciptakan motif batik, dengan selera pribadi yang memiliki memiliki arti penting dalam kehidupan sehari - hari. Batik kreasi ini tidak berpatokan pada corak batik keratin, pesisiran, maupun batik daerah lainnya.

\section{Sejarah Hari Ibu}

Untuk mengenang jasa-jasa para ibu yang begitu besar, ditetapkanlah hari ibu yang jatuh pada tanggal 22 Desember sebagai Hari Ibu Nasional. Momen tersebut merupakan tonggak sejarah bagi Indonesia untuk memproklamirkan ke negara di dunia akan pentingnya peran ibu dalam andil membangun bangsa dan negara. Penetapan ini dilakukan pada masa Presiden Soekarno diikuti dengan penerbitan Dekrit Presiden No. 316 tahun 1953.

\section{METODE PENELITIAN}

Metode penelitian untuk mencitptakan karya menggunakan metodelogi desain Vijay Kumar (Kumar, 2016) dengan teori tujuh mode proses desain inovasi diantaranya :

1. Memahami Tujuan

2. Mengetahui Konteks

3. Mengenal Masyarakat

4. Menyusun Gagasan

5. Mengeksplorasi Konsep

6. Menyusun Solusi

7. Merealisasikan Penawaran

Dari ketujuh mode proses desain tersebut, penulis tidak melakukan proses desain secara berurutan, tetapi sesuai kebutuhan yang dilakukan selama proses berfikir dalam pembuatan desain karya.

- Mengetahui konteks :

Moment Hari Ibu, dimaknai dengan mengungkapkan rasa kasih sayang anak terhadap ibu. Biasnya memberikan ucapan selamat, kado, bunga, bahkan membebas tugaskan pekerjaan rumah kepada ibu. Ada juga dengan berdandan menggunakan kebaya dengan rambut disanggul.

- Mengenal masyarakat:

Setelah melakukan pengamatan di lingkungan sosial, yang kerap terjadi di era saat ini, dengan perkembangan teknologi beserta aplikasiya pada moment Hari Ibu kaum millenial ramai mengupload foto kebersamaan dengan ibunya di sosial media serta caption kaliamat mutiara, hanya untuk pencitraan. Disinilah mulai terhihat pergeseran makna moment Hari Ibu

- Memahami tujuan :

Penulis bertujuan ingin menyampaikan perasaan kasih sayang terhadap ibu sebagai bentuk apresiasi atas jasanya selama ini dan juga ingin menyadarkan kaum muda khususnya millennial akan makna kasih sayang pada moment Hari Ibu 


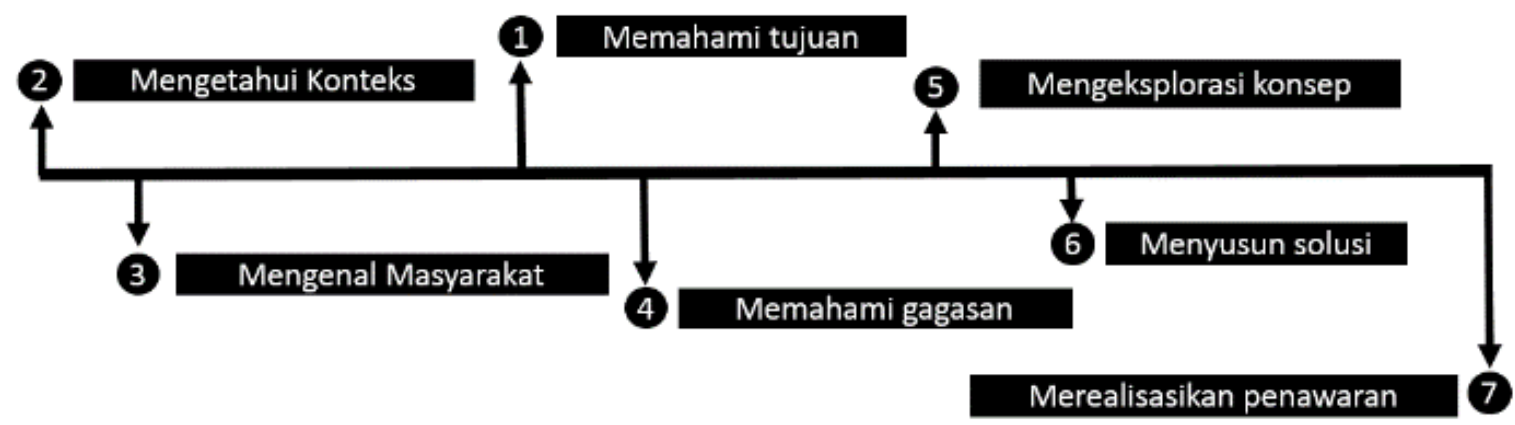

Gambar 1. Bagan tujuh mode proses desain ( sumber : 101 metode desain Vijay Kumar )

bukan sekedar ajang pencitraan di media sosial dengan mengupload foto.

- Memahami gagasan:

Motif batik ini adalah sebuah simbol bentuk kasih sayang anak terhadap ibu dengan menggunakan pengubahan bentuk distorsi. Didalamnya ada elemen gambar ibu dan anak yang sedang menatap serta merangkul. Distorsi ialah pengubahan bentuk yang bertujuan untuk lebih menonjolkan karteristik visual objek, sehingga mendapatkan bentuk lain yang sesuai dengan konsep estetik senimannya. (Suryo Suradjijo, 1999: 17). Dengan itu penulis menggunakan bentuk distorsi sebagai tampilan pengubahan bentuk karya ekspresi seorang kasih sayang anak terhadap ibunya.

- Mengeksplorasi konsep :

Dapat menjadi trend motif sebagai bentuk memaknai hari - hari besar seperti Hari Pahlawan, Hari Raya Idul Fitri, Natal, Hari Pendidikan Nasional, Hari Lahir Pancasila

- Menyusun solusi :

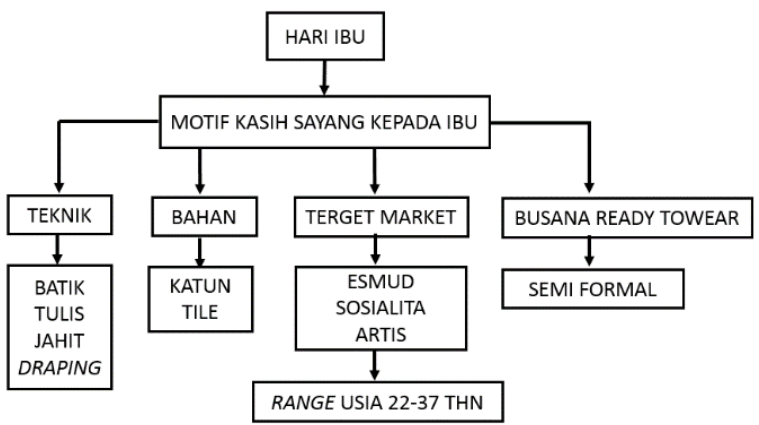

Gambar 2. Bagan menyusun soliso proses desain (sumber : Fegelia Rahmadani)

- Merealisasikan penawaran:

Dari prototype atau sketsa motif dan desain busana sampai menjadi hasil produk dalam bentuk busana ready towear

\section{PEMBAHASAN}

Berangkat dari pengalaman empiris yang dialami penulis yang diyakini turut dialami oleh semua orang. Hubungan yang terjalin antara anak dan ibu yang menimbulkan rasa kasih sayang. Kasih sayang tersebut muncul dari kedekatan secara intim, namun seiring masa yang berlalu tidak sedikit terjadinya perbedaan pendapat di dalam hubungan tersebut. Akan tetapi sebagai anak haruslah tetap menyayangi ibu kita, sebab karena jasa ibulah kita bisa lahir dan berkembang sampai sekarang ini. Kasih sayang ibu terhadap anak tentu berbeda dengan kasih sayang anak terhadap ibunya.

Penulis bertujuan ingin menyampaikan perasaan kasih sayang terhadap ibu sebagai bentuk tanda terima kasih serta apresiasi atas jasanya selama ini, dan juga ingin menyadarkan kaum muda khususnya millennial akan makna kasih sayang pada moment Hari Ibu bukan sekedar ajang pencitraan di media sosial dengan mengupload foto.

Bentuk dari ungkapan kasih sayang kepada ibu, penulis yang juga sebagai anak menuangkan ide baru kedalam sebuah motif batik kreasi, dengan menggunakan bentuk distorsi sebagai tampilan pengubahan bentuk karya ekspresi seorang kasih sayang anak terhadap ibunya. Motif batik ini adalah sebuah simbol bentuk kasih sayang anak terhadap ibu dengan menggunakan pengubahan bentuk distorsi. Didalamnya ada elemen gambar ibu dan anak yang sedang menatap serta merangkul.

Proses penciptaan karya sebagai berikut :

1. Sumber ide dari pengalam empiris pribadi dan empati terhadap orang lain tentang kasih sayang anak terhadap ibu.

2. Membuat sketsa motif yang di dalamnya terdapat element gambar ibu dan anak yang sedang menatap serta merangkul menjadi sebuah simbol bentuk kasih sayang dengan menggunakan pengubahan bentuk distorsi. 


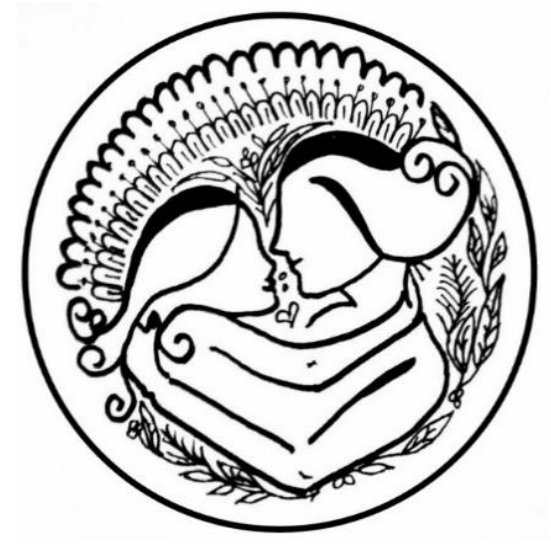

Gambar 3. Motif kasih sayang ibu ( sumber : Fegelia Rahmadani)

3. Mengkombinasikan motif dengan ornament lain untuk menjadi desain selembar kain

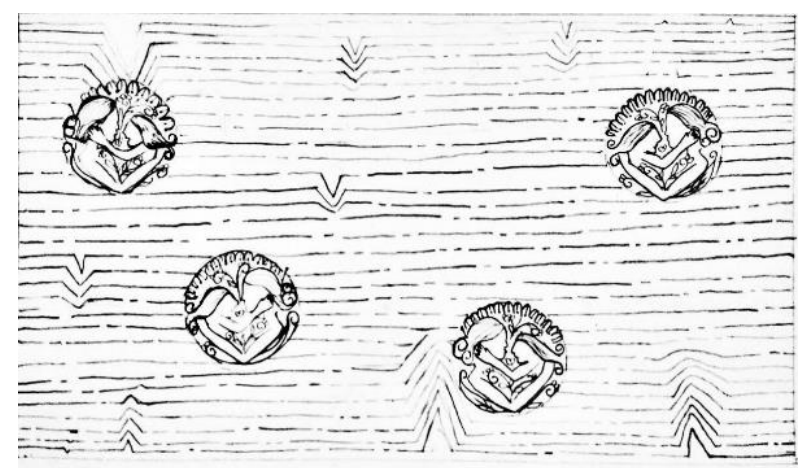

Gambar 4. Kombinasi motif dan ornamen lainnya ( sumber : Fegelia Rahmadani )

4. Membuat beberapa alternatif desain busana ready towear dengan motif kasih sayang ibu.

5. Melakukan approval dengan dosen pengampu.
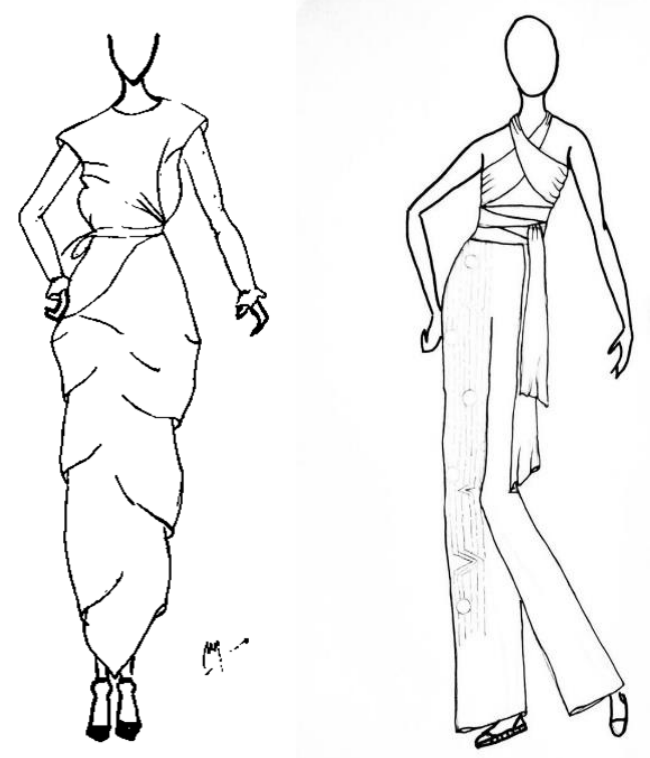

Gambar 5. Sketsa desain ( sumber : Fegelia Rahmadani )
6. Pemilihan kain serat alami yaitu katun slik yang memili tekture halus dan sedikit mengkilap sehingga nyaman di kulit.

7. Membersihkan kain dari pabrik uyang biasanya masih mengandung kanji, menggunakan air panas yang dicampur dengan merang atau jerami.

8. Memgambar pola motif di atas kain menggunakan pensil

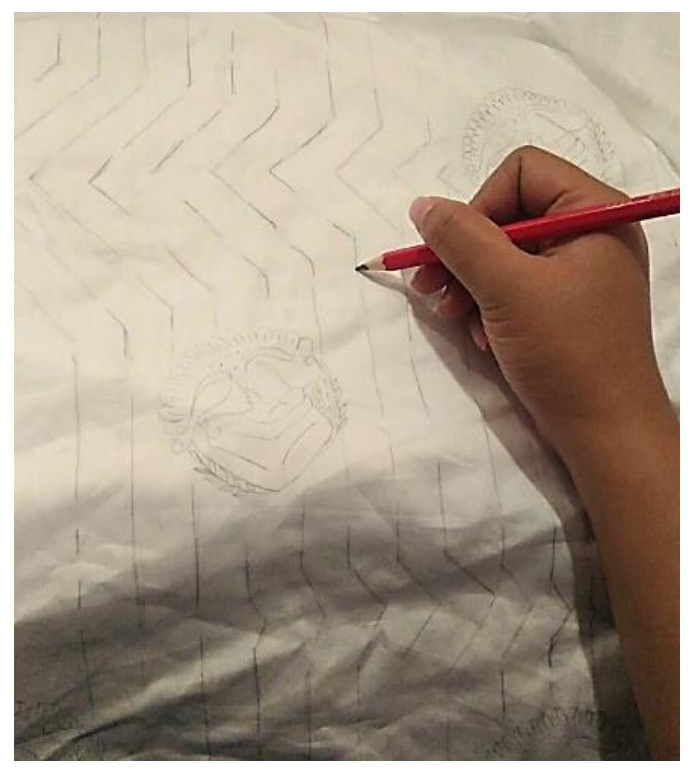

Gambar 6. Menjiplak pola motif pada kain ( sumber : Fegelia Rahmadani )

9. Membatik, menempelkan malam batik pada pola yang telah di gambar menggunakan canting.

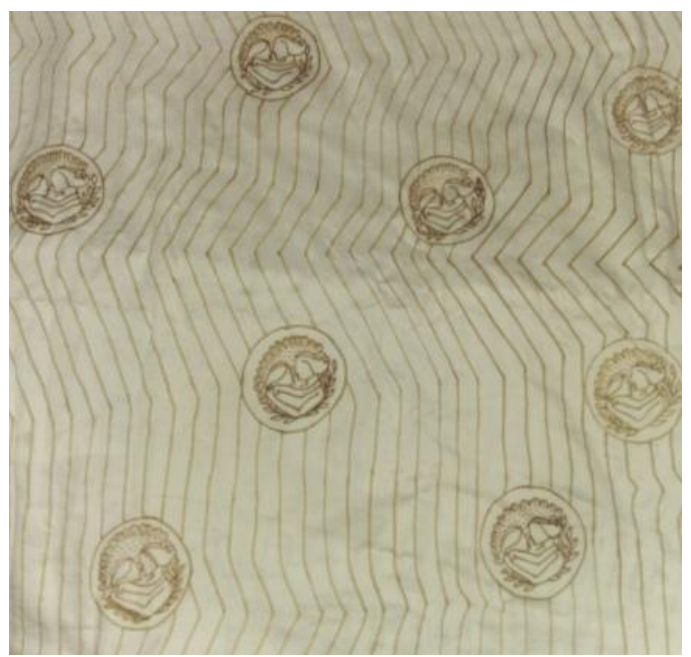

Gambar 7. Kain yang sudah dibatik menggunakan malam ( sumber : Fegelia Rahmadani )

10. Mewarna dengan mencelup kain yang telah dibatik dengan malam ked lam cariran pewarna sintesis. 


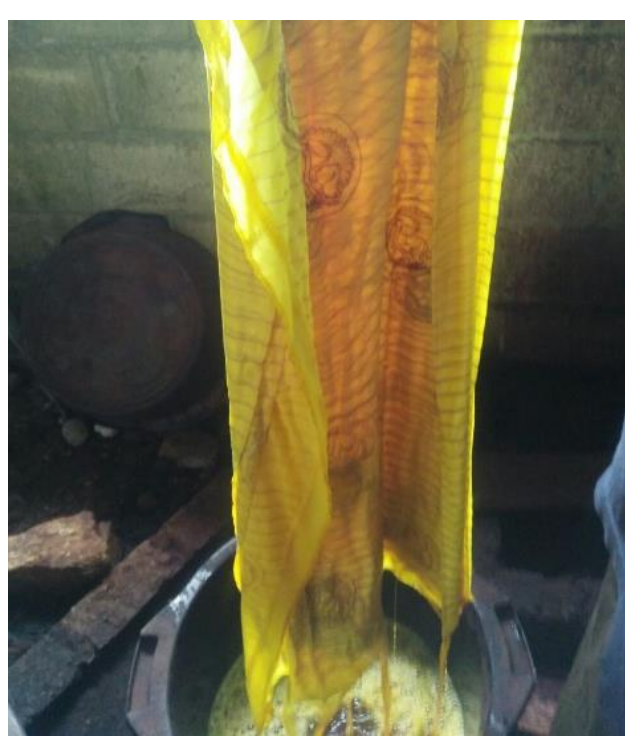

Gambar 8. Pencelupan warna sintesis ( sumber : Fegelia Rahmadani)

11. Ngelorot, proses menghilangkan malam pada kain dengan air mendidih diberi sedikit soda ash agar bersih.

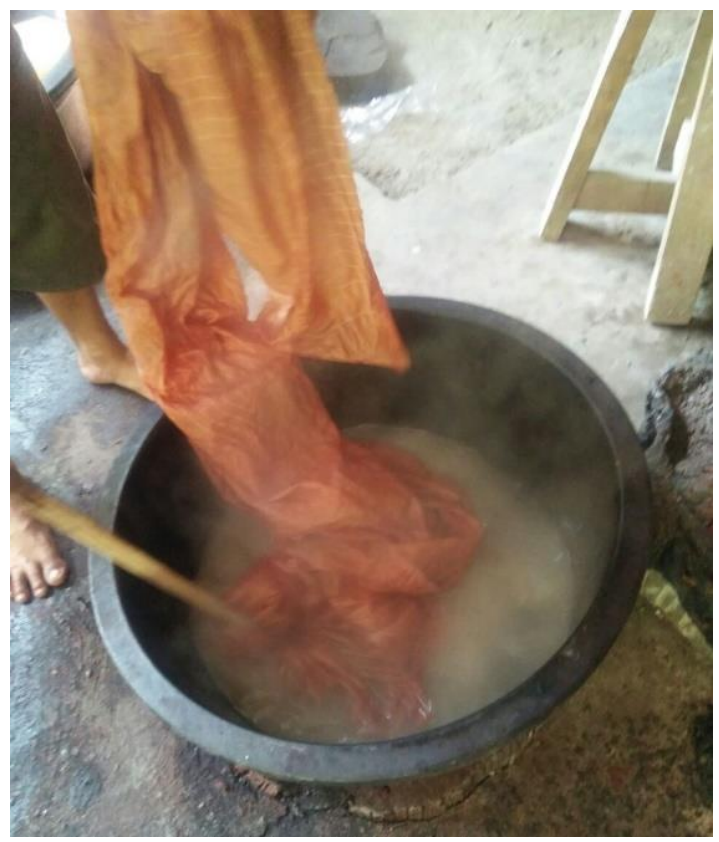

Gambar 9. Ngelorot, menghilangkan malam dengan air panas yang dicampur soda ash (sumber : Fegelia Rahmadani )

12. Bilang dengan air besih kemudian di jemur di tempat yang teduh, jangan terkena langsung matahari.

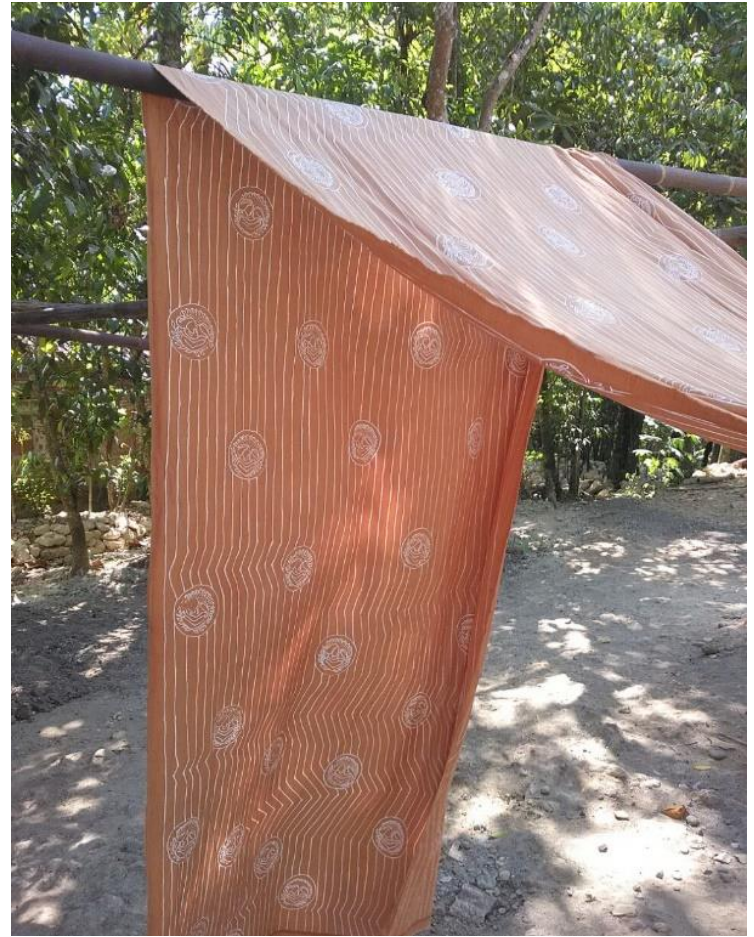

Gambar 10. Kain dijemur di tempat teduh ( sumber : Fegelia Rahmadani)

13. Setelah kain batik kering, membuat pola busana pada kain

14. Draping kain batik membentuk sesuai keinginan 15. Jahit pola untuk meyatukan agar menghasilkan busana yang utuh

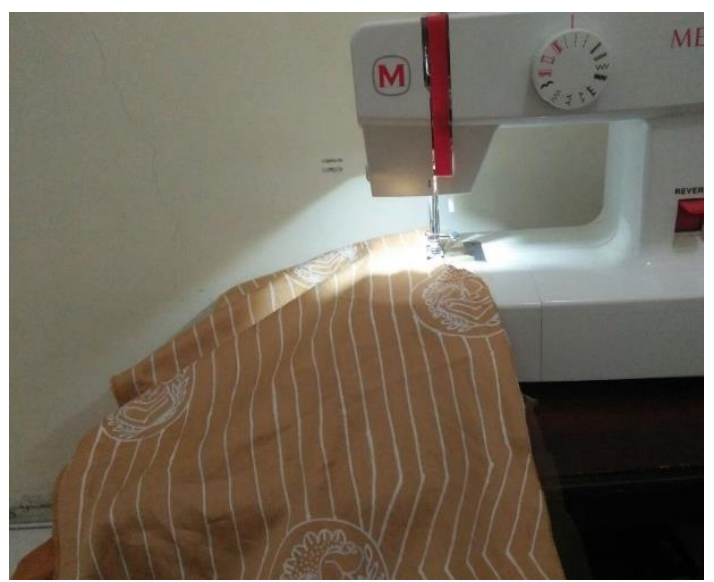

Gambar 11. Pola busana dijahit ( sumber : Fegelia Rahmadani)

16. Tambahkan bahan pendukung seperti tile, mutiara dan karet untuk menabah nilai estetik pada busana. 


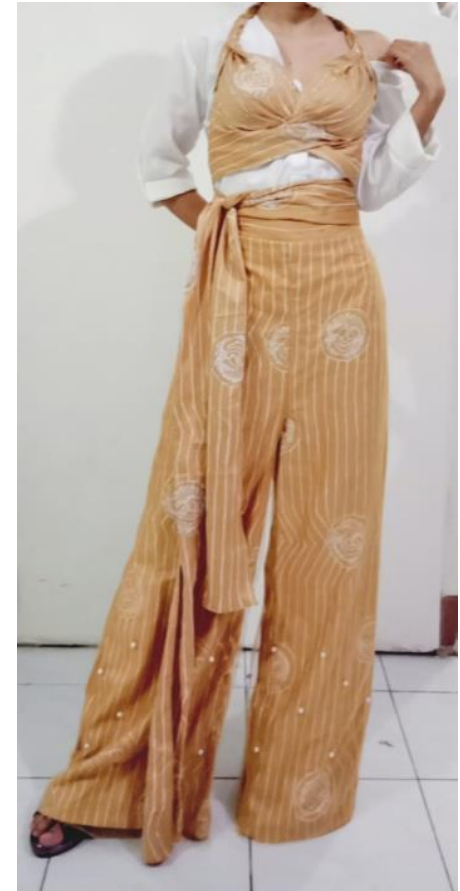

Gambar 12. Hasil produk busana yang dipakai model

(sumber : Fegelia Rahmadani)

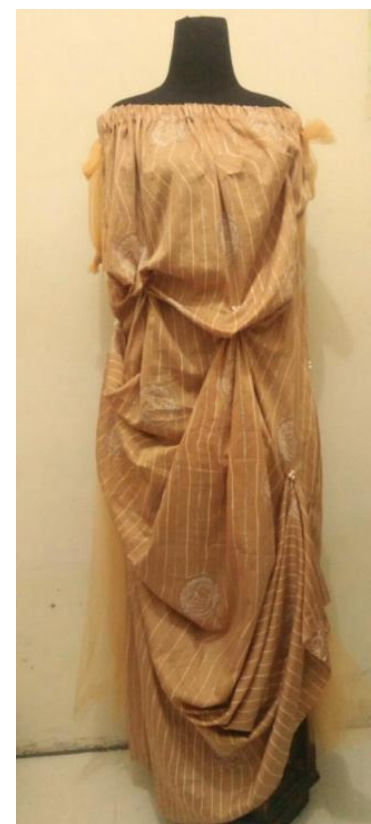

Gambar 13. Hasil produk busana memakai mannequin

( sumber : Fegelia Rahmadani )

\section{KESIMPULAN}

Membuat karya dengan mengusung tema kasih sayang kepada ibu ini, merupakan suatu keinginan penulis untuk dapat memberikan sesuatu makna pada motif batik tersebut. Dengan tema tersebut tidak hanya terjadi sebagai pengalaman pribadi saja, melainkan semua orang yang lahir dari seorang ibu, namun haruslah memiliki rasa empati yang tingggi agar dapat mewakili pesan dalam sebuah motif atau karya lainnya. Meskipun masih banyak kekurangan penulis sangat menyadarinya.

Selama proses produksi berlangsung, ada perubahan pada desain dengan hasil akhir dikarenakan poses berfikir kreatif yang spontanitas dan faktor yang lain..

\section{UCAPAN TERIMA KASIH}

Puji Syukur Alhamduliah kepada Allah SWT, termakasih kepada dosen pembimbing bapak Dr. Timbul Raharjo, M.Hum. terimakasih kepada kedua orang tua penulis yang telah memberi dukungan moral maupun materi sehingga penelitian ini dapat selesai tepat waktu.

\section{DAFTAR PUSTAKA}

Kumar, V. (2016). 101 Metode Desain. Jakarta: Elex Media Komputindo.

Ali, L. (1999). Kamur Besar Bahasa Indonesia. Jakarta: Balai Pustaka.

Asmito. (1992). Sejarah Kebudayaan Indonesia. Semarang: IKIP Semarang Press.

Hamzurt. (1994). Batik Klasik. Jakarta: Djambatan. Kumar, V. (2016). 101 Metode Desain. Jakarta: Elex Media Komputindo.

Wulandari, A. (2011). Batik Nusantara : makna filosofis, cara pembuatan, dan industi batik. Yogyakarta: Andi.

Musman, A., \& Airin, A. B. (2011). Batik Warisan Adilubung Nusantara. Yogyakarta: G-Media.

Warsito, T. (2008). Batik Sebagai Aset Diplomasi Kebudayaan Indonesia. Makalah Seminal Nasional Kebangkitan Batik Indonesia dengan Tema :Batik di Mata Bangsa Indonesia dan Dunia. Yogyakarta. 